\title{
Toksinlerle olușan rekürren perineal eritem: Olgu sunumu ve literatür değerlendirmesi
}

\author{
Recurrent toxin-mediated perineal erythema: $A$ case report and literature review
}

Sema Aytekin

S. B. Haydarpașa Numune Eğitim ve Araștırma Hastanesi, Deri ve Zührevi Hastalıklar Kliniği, İstanbul, Türkiye

\section{Özet}

Toksinlerle oluşan rekürren perineal eritem (TORPE), stafilokok ve streptokok süperantijenleriyle oluşan, kendiliğinden iyileşen bir hastalıktır. İnguinal bölge, perine veya alt abdomende yerleşen, genellikle asemptomatik, iyi sınırlı deskuamatif eritemle karakterizedir. Hastalığın diğer tipik özellikleri ise akral ödem, çilek dil ve mukozittir. TORPE, antibiyotik tedavisini izleyen günlerde hızla iyileşir. Burada 10 yaşında, çilek dil ve rekürren deskuamatif perineal eritem bulunan TORPE'li bir olgu sunulmaktadır. Ayrıca toksinle oluşan ve/veya perineal eritem bulunan hastalıklar literatürde değerlendirilmiştir. Ekzantemli pediyatrik hastalar genellikle aile hekimleri veya pediatristler, nadiren de dermatologlar tarafından değerlendirilir. Biz bu olguyla dermatologların dikkatini çekmek istedik. (Türkderm 2013; 47: 236-8)

Anahtar Kelimeler: Perineal eritem, toksinlerle oluşan rekürren perineal eritem, Baboon sendromu, simetrik ilaçla ilişkili intertrijinöz ve fleksural ekzantem, SDRIFE

\section{Summary}

Recurrent toxin-mediated perineal erythema (RTPE) is a benin self-limiting mucocutaneous disorder caused by super antigens produced by staphylococci and streptococci. It is characterized by generally asymptomatic well-demarcated desquamating erythema involving the perineum, groin or lower abdomen. Other typical features such as acral edema, strawberry tongue and mucositis are often present. RTPE rapidly improves after antibiotic therapy. Herein, we report a 10-year-old boy with RTPE who presented with strawberry tongue and recurrent desquamating perineal erythema. We also reviewed the literature on diseases that are toxin mediated and/or presenting with perineal erythema. Pediatric patients with exanthema are primarily seen by pediatricians or family physicians, and rarely by dermatologists. With this report, we wish to draw the attention of dermatologists. (Turkderm 2013; 47: 236-8)

Key Words: Perineal erythema, recurrent toxin-mediated perineal erythema, Baboon syndrome, symmetrical drug-related intertriginous and flexural exanthema, SDRIFE

\section{Giriş}

Toksinlerle oluşan rekürren perineal eritem (TORPE), genç erişkinler ve çocuklarda görülen streptokok veya stafilokok süperantijenleriyle oluşan bir deri hastalığıdır 1-3. Süperantijenler nonspesifik $T$ hücre proliferasyonunu stimüle eder ve dolanan lenfositlerin \%20-30'unu aktive eder. Bu şekilde T hücrelerinde artış, TNF $\alpha$, IL-1 ve IL-6 gibi sitokinlerin yoğun salınımına neden olurlar. Oluşan sitokinler ateş, hipotansiyon, kusma, diyare ve deri erüpsiyonları gibi birçok farklı klinik belirtiye neden olur. Streptokok veya stafilokok süperantijenleriyle Kawazaki hastalığı (KH),

Yazışma Adresi/Address for Correspondence: Dr. Sema Aytekin, S. B. Haydarpaşa Numune Eğitim ve Araştırma Hastanesi, Deri ve Zührevi Hastaliklar Kliniği, İtanbul, Türkiye Tel.: +90 412248801 E-posta: semaaytekin@yahoo.com Geliş Tarihi/Received: 23.04.2011 Kabul Tarihi/Accepted: 24.08.2011 
Kawazaki benzeri sendrom, streptokoksik veya stafilokoksik toksik şok sendromu (TŞS), stafilokoksik haşlanmış deri sendromu (SHDS), kızıl, dirençli eritematöz deskuamatif hastalık ve TORPE gibi birçok hastalık oluşmaktadır1-6. Ayrıca bu mikroorganizmalar psoriazis, atopik dermatit ve kutanöz $T$ hücreli lenfoma gibi hastalıkların patogenezinde rol oynamaktadırlar3,6. PubMed taramasında TORPE ile ilgili çok az sayıda makale mevcut olup, bu konuyla ilgili türkçe makale bulunamamıştır. $\mathrm{Bu}$ nedenle olgu sunumumuzla toksinlerle oluşan rekürren perineal eritem kliniği ayrıntılı olarak değerlendirilmiştir.

\section{Olgu}

On yaşında erkek çocuğu; boğaz ağrısı ve sonrasında dilde ve kasıklarda oluşan kızarıklık şikayetiyle polikliniğimize müracaat etti. Bir yıl ve 2 ay önce olmak üzere iki kez benzer şekilde, genel durum bozukluğu ve ateş olmaksızın boğaz ağrısı ve 24 saat içerisinde dilde kızarıklık ile inguinal bölgeden başlayıp, gluteal bölgeye yayılan, hafif yanma şikayetinin olduğu eritem oluşumu hikayesi vardı. Lezyonlar oluştuktan sonra ateş düşürücü ve antibiyotik kullanım hikayesi saptandı. Hastanın genel durumu iyi, ateş ve arteryel tansiyon değerleri normal sınırlarda idi. Oral mukoza muayenesinde, kırmızı çilek dili ve farinkste hiperemi saptandı (Resim 1). Perine, inguinal, pubik bölge, gluteal kıvrım ve üst kısımlarında simetrik, keskin kenarlı, eritemli peç ve orta kısımdan başlayan deskuamasyon mevcuttu (Resim 2, 3). Ayrıca sol inguinalde yaklaşık $2 \times 5 \mathrm{~cm}$ ebatında hafif hiperpigmente zeminde küçük koyu kahverengi maküllerden oluşan nevus spilus lezyonu izlendi. El ve ayaklar dahil diğer deri bölgeleri doğaldı. Laboratuvar değerlendirilmesinde nötrofili ağılıkıı lökositoz saptandı. Kan biyokimyası, trombosit sayısı, eritrosit sedimantasyon hızı, C-Reaktif protein normal sınılarda idi. Boğaz kültüründe Streptokokkus piyojenes üredi. Oral amoksisilin klavulanat tedavisi ile lezyonlar yaklaşık 10 günde rezidüel hiperpigmentasyon bırakmaksızın geriledi (Resim 4). Hastaya penisilin proflaksisi başlandı. Dört aydır takip edilen hastada rekürrens görülmedi.

\section{Tartışma}

Toksinlerle oluşan rekürren perineal eritem, 1996 yılında Manders ve arkadaşları tarafından tanımlanmıştır. Tanımlanan iki vakanın birinde streptokokal pirojenik toksin A ve B, diğerinde ise toksik şok sendromu toksin 1 gösterilmiştir ${ }^{1}$. Toksinlerle oluşan eritemlerin lokalize klinik bir varyantı olarak değerlendirilebilir3. Hastalığın tipik özelliği, sıklıkla bakteriyel faranjit sonrası aniden oluşan diffüz perineal, inguinal veya abdominal deskuamatif eritemdir. Genellikle semtomsuzdur, bazen hafif kaşıntı ve yanma ile birlikte olabilir. Çilek dil ve mukozit gibi mukozal değişiklikler ile birlikte sıklıkla el ve ayaklarda ödem ile deskuamasyon görülür1-3. Olgumuzda TORPE kliniği toplam 3 kez oluşmuş ve hiçbir atakta el ve ayaklarda ödem, deskuamasyon oluşmamıştı. TORPE'de ateş, hipotansiyon gibi klinik belirtiler yokken, bazı olgularda diyare görülebilir. Akut ataklar sırasında genellikle farinks, bazen de deri sürüntü kültürlerinde toksin üreten streptokokkus piyojenes veya stafilokokkus aereus ürer. Lokalize eritematöz bölgenin bakteriyel kültürleri negatiftir. Hastalık sistemik belirtiler olmaksızın benin seyirli olup antibiyotik tedavisi sonrasında hızla iyileşir1-4.

Patrizi ve arkadaşları tarafından TORPÉli 11 olgunun değerlendirildiği çalışmada olguların tamamında perineal eritem, birinde perianal eritem, 4'ünde el veya ayaklarda eritem, 7'sinde çilek dil görünümü bildirilmiştir. Olgularının 3'ünde rekürrens hikayesi, 3'ünde izlemde rekürrens saptanırken, 8 olgu hastalığın ilk atağı olarak değerlendirilmiştir². Bizim olgumuzda olduğu gibi tanı klinik olarak konulmuş, streptokok ve stafilokok toksinleri çalışılmamıştır. Levy bu makaleyle ilgili editöryal yazısında toksinlerin çalışılmamış olmasını eleştirirken, lezyonların lokalize olması, hastanın genel durumunun iyi olması, laboratuvar değerlerinin normal olmasıyla KH'nın dışlandığını da belirtmiştir7. Son çalışmalarda streptokok ve stafilokokal süperantijenlerin $\mathrm{KH}$ ile ilişkisi desteklenmektedir ${ }^{5}$. Kawasaki hastalığı,

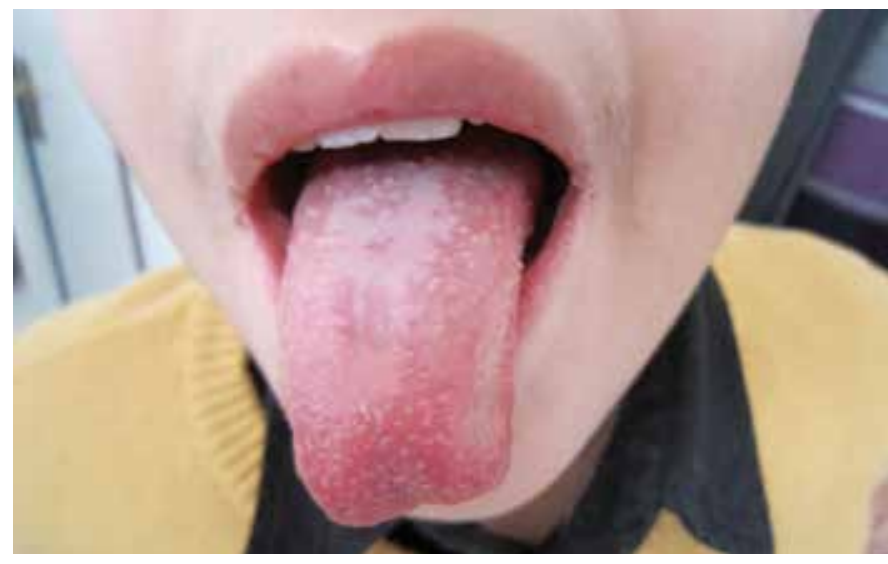

Resim 1. Olguda tipik çilek dil görünümü

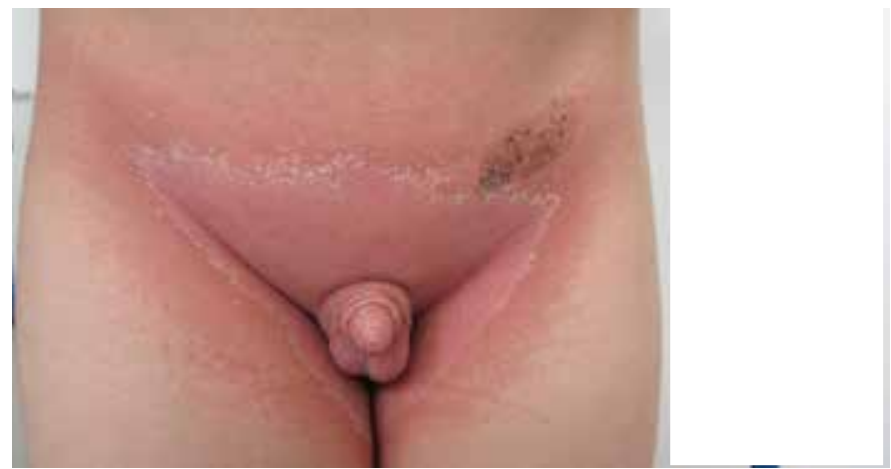

Resim 2. Pubik bölge ve inguinal bölgede ortadan deskuame olan eritemli peç.

* nevus spilus

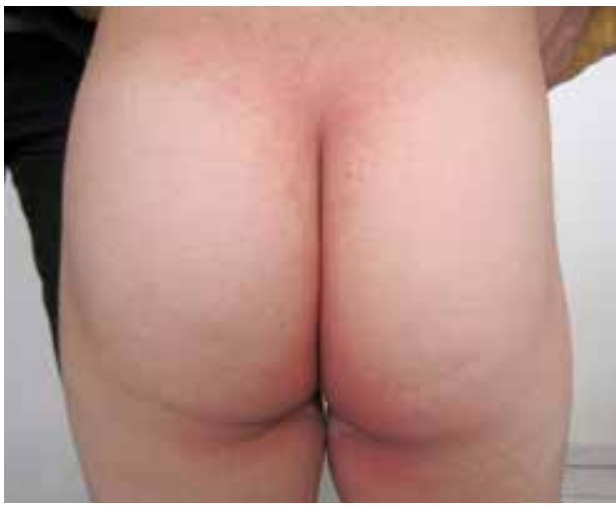

Resim 3. Gluteal kıvrımlarda eritem 
tedavi edilmeyen çocukların \%25'inde akkiz kalp hastalığına neden olan, akut gelişen bir multisistem hastalığıdır. Nedeni açıklanamayan, beş günden daha uzun süren yüksek ateş varlığında $\mathrm{KH}$ düşünülmeli ve tanı kriterleri açısından değerlendirilmelidir. Perineal eritem tanı kriterleri arasında yer almasa da, akut Kawasaki hastalığı bulunan 58 yenidoğan veya çocuk hastanın \%67'sinde saptanmıştır3,8. Toksinlerle oluşan rekürren perineal eritem, Kawasaki hastalığından farklı olarak kendini sınırlayan benin bir durumdur. Hastanın kliniği ve laboratuvar bulgularına göre $\mathrm{KH}$ açısından bazı olgularda ekokardiyografi yapılması gerekebilir. Patrizi ve arkadaşları çalışmalarında Kawasaki hastalığı ile toksinlerle oluşan rekürren perineal eritem arasındaki temel farklılıkları belirtmişlerdir (Tablo 1)2.

Perianal streptokokal dermatit (PSD), küçük çocuklarda görülen, keskin kenarlı perianal eritem, ağrılı defekasyon, konstipasyon ve kanlı dışkı ile karakterizedir. Perianal deri kültüründe $\beta$ hemolitik streptokok ürer. Perianal streptokokal dermatite bakterilerin oluşturduğu toksinlerle kliniğe TORPE de eklenebilir. Perineal eritemle gelen olgularda perianal bölge muayenesi yapılmalı ve ağrılı defekasyon sorgulanmalıdır3,9.

Perineal ve/veya inguinal eritem, 1984 yılında tanımlanan nadir görülen nikel, civa ve ilaçlar gibi Tip IV alerjenlere oral maruziyet sonrası oluşan sistemik kutanöz bir reaksiyon olan Baboon Sendromunu (BS)

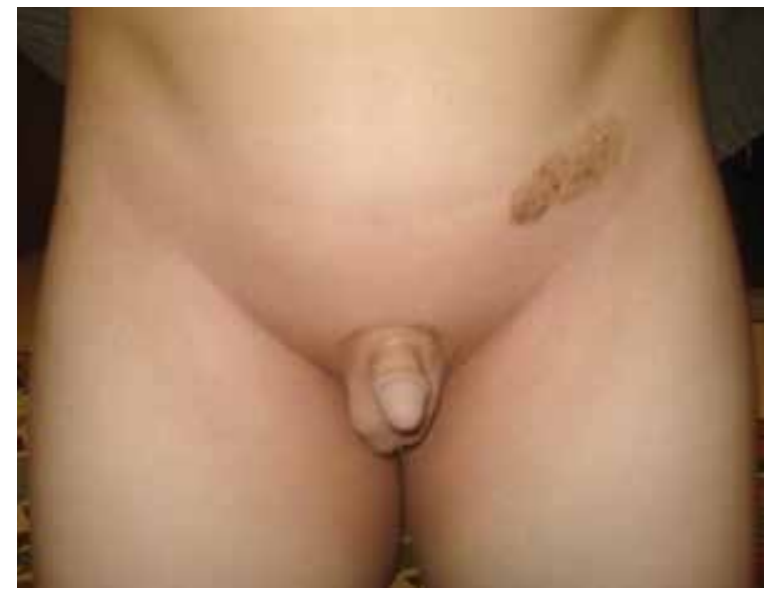

Resim 4. Pubik ve inguinal bölgenin 10 gün sonraki görünümü

Tablo 1. Kawasaki hastalığı ve toksinlerle oluşan rekürren perineal eritem arasındaki temel klinik ve laboratuvar farklılıklar2

\begin{tabular}{|lll|}
\hline & KH & TORPE \\
\hline Yaş & <2yaş & 3-6yaş \\
\hline Ateş ( $\geq 5$ gün süre) & Var & Yok \\
\hline Polimorfik ekzantem & Var & Yok \\
\hline Perineal eritem & Var & Daima var \\
\hline Konjunktivit & Var & Nadir \\
\hline Çilek dil ve oral mukoza değişiklikleri & Var & Var \\
\hline Servikal akut makrolenfadenopati & Var & Yok \\
\hline Palmoplantar eritem ve deskuamasyon & Var & Var \\
\hline Rekürrens & Nadir & Sıklıkla var \\
\hline $\begin{array}{l}\text { Laboratuvar değişiklikler } \\
\text { (Elektrokardiyografi, trombosit sayısı gibi) }\end{array}$ & Sık & Nadir \\
\hline
\end{tabular}

da düşündürmelidir10. Genellikle topikal uygulama sonrası oluşan duyarlanma ile etkene tekrar topikal veya sıklıkla sistemik maruziyet sonrası klinik oluşur. Baboon Sendromu yerine 2004 yılından itibaren hastalığı tanımlayan özelliklerin kısaltması olan SDRIFE (simetrical drug-related intertriginous and flexural exanthem) terimi kullanılmaya başlanmıştır ${ }^{11}$. Hastalığın tanısında 5 klinik özellik tanımlanmıştır. (i) Sistemik olarak ilaca tekrar maruziyet sonrası olması. (ii) Kalçada keskin kenarlı eritem ve/veya uylukta $\vee$ şeklinde eritem. (iii) En az bir büyük fleksural tutulum. (iv) Simetri. (v) Sistemik semptom olmaması gibi. Beta-laktam antibiyotikler başta olmak üzere birçok ilaç ile oluşabilir. "Patch" test ile tanı desteklenebilir. Eritem üzerinde deskuamasyon hastalığın bir özelliği değildir. Fiks ilaç erupsiyonundan farklı olarak iyileşme sonrası hiperpigmentasyon oluşmaz'11-14

Olgumuzda eritem öncesi ilaç kullanım hikayesi olmaması, lezyon ortasından başlayan deskumasyon varlığı, çilek dil birlikteliği, boğaz kültüründe Streptokokkus piyojenes üremesiyle SDRIFE ekarte edilmiş ve toksinlerle oluşan rekürren perineal eritem tanısı konulmuştur. Perineal eritem varlığında sadece farinks kültürü değil, perianal deriden, varsa diğer deri lezyonlarından kültür alınmalıdır. Illk atak sırasında gelen hastalar olabileceği için tanı için rekürrens şart değildir ${ }^{4}$. Sistemik belirtiler ve ateş varlığında Kawasaki hastalığı dışlanmalıdır. Ülkemizde döküntülü pediyatrik hastalar genellikle aile hekimleri veya pediatristler tarafından değerlendirilmekte olup, toksinlerle oluşan rekürren perineal eritem olguları çoğunlukla yanlış olarak ilaç erüpsiyonu tanısı almaktadır. Bu makalede perineal eritem ayırıcı tanısı da yapılarak toksinlerle oluşan rekürren perineal eritem kliniği değerlendirilip, bu olguyla dermatologların dikkatini çekmek istenmiştir.

\section{Kaynaklar}

1. Manders SM, Heymann WR, Atillasoy E, Kleeman J, Schlievert PM: Recurrent toxin-mediated perineal erythema. Arch Dermatol 1996;132:57-60.

2. Patrizi A, Raone B, Savoia F, Ricci G, Neri I: Recurrent Toxin-Mediated Perineal Erythema: Eleven Pediatric Cases. Arch Dermatol 2008;144:239-43.

3. Macias ES, Pereira FA, Rietkerk W, Safai B: Superantigens in Dermatology. J Am Acad Dermatol 2011;64:455-72.

4. Manders SM: Toxin-mediated streptococcal and staphylococcal disease. J Am Acad Dermatol 1998;39:383-98.

5. Matsubara K, Fukaya T: The role of superantigens of group A Streptococcus and Staphylococcus aureus in Kawasaki disease. Curr Opin Infect Dis 2007;20:298-303.

6. Ergin S, Elçin G, Şahin S: Grup B Streptokoklara bağlı perianal sellülit sonrası tetiklenen bir guttat psoriazis olgusu. Turkderm 2009;3:70-2.

7. Levy LM: Recurrent Toxin-Mediated Perineal Erythema in Children. Is That All There Is? Arch Dermatol 2008;144:245.

8. Friter BS, Lucky AW: Perineal eruption of Kawasaki syndrome. Arch Dermatol 1988; $124: 1805-10$

9. H. Jongen J, Eberstein A, Peleikis HG, Kahlke $V$, Herbst RA: Perianal streptococcal dermatitis: an important differential diagnosis in pediatric patients. Dis Colon Rectum 2008;51:584-7.

10. Andersen $\mathrm{KH}$, Hjorth $\mathrm{N}$, Menne T: The Baboon syndrome: systemicallyinduced allergic contact dermatitis. Contact Dermatitis 1984;10:97-100.

11. Hauserman $P$, Harr T, Bircher AJ: Baboon syndrome resulting from systemic drugs: is there sdrife between SDRIFE and allergic contact dermatitis syndrome? Contact Dermatitis 2004;51:297-310.

12. Handisurya A, Stingl G, Wöhrl S: SDRIFE (baboon syndrome) induced by penicilin. Clinical and Experimental Dermatology 2008;34:355-7.

13. Akay BN, Sanlı H: Symmetrical Drug-Related Intertriginous and Flexura Exanthem Due To Oral Risperidone. Pediatric Dermatology 2009;26:214-6.

14. Utaş $S$, Ferahbaş $A$ : Baboon syndrome and segmental vitiligo coexistence. Turk J Pediatr 2009;51:392-4. 